\title{
RESEARCH
}

Open Access

\section{Neurological complications after pediatric cardiac surgery}

\author{
Ergin Arslanoğlu ${ }^{1 *}$ (D, Kenan Abdurrahman Kara', Fatih Yiğit ${ }^{1}$, Cüneyt Arkan', Ufuk Uslu², Ömer Faruk Şavluk²,
} Abdullah Arif Yılmaz ${ }^{1}$, Eylem Tunçer ${ }^{1}$, Nihat Çine ${ }^{1}$ and Hakan Ceyran ${ }^{1}$

\begin{abstract}
Background: The number of pediatric patients who survive open-heart surgery has increased in recent years and the complications seen in this patient group continue to decrease with each technological advance, including new surgical and neuroprotective techniques and the improvement in surgeons' experience with this patient population. However, neurological complications, which are the most feared and difficult to manage, require longterm follow-up, and increase hospital costs remain a leading cause of mortality and morbidity in this cohort.

Results: We evaluated the neurological physical examination, cranial computed tomography (CT), and magnetic resonance (MRI) records of 162 pediatric patients with neurological symptoms lasting more than $24 \mathrm{~h}$ after undergoing heart surgery in our clinic between June 2012 and May 2020. The patients' ages ranged from 0 to 205 months, with a mean of $60.59 \pm 46.44$ months.

Of the 3849 pediatric cardiac surgery patients we screened, 162 had neurological complications in the early period (the first 10 days after surgery). The incidence was calculated as 4.2\%; 69 patients (42.6\%) experienced seizures, 17 (10.5\%) experienced confusion, 39 (24.1\%) had stupor, and 37 (22.8\%) had hemiparesis. Of the patients who developed neurological complications, 54 (33.3\%) died. Patients with neurological complications were divided into 3 groups: strokes $(n=90)$, intracranial bleeding $(n=37)$, and no radiological results $(n=35)$. Thirty-four patients (37.8\%) in the stroke group died, as did $15(40 \%)$ in the bleeding group, and $5(14.3 \%)$ in the no radiological results group.
\end{abstract}

Conclusions: Studies on neurological complications after pediatric heart surgery in the literature are currently insufficient. We think that this study will contribute to a more detailed discussion of the issue. Responses to neurological events and treatment in the pediatric group may differ compared to the adult age group. Primary prevention methods should be the main approach in combating neurological complications; their formation mechanisms should be carefully monitored and preventive treatment strategies should be developed.

Keywords: Cerebrovascular event, Hemiparesis, Neurological complications, Pediatric open-heart surgery, Seizure, Unconsciousness

\footnotetext{
* Correspondence: erginarslanoglu@gmail.com

${ }^{1}$ Pediatric Cardiovascular Surgery Department, Kartal Kosuyolu High

Education and Training Hospital, Cevizli, 2, Denizer Caddesi, Cevizli Kavşağı,

34865 Kartal, Istanbul, Turkey

Full list of author information is available at the end of the article
}

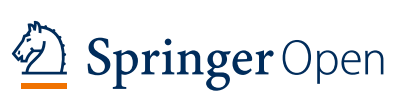

(c) The Author(s). 2021 Open Access This article is licensed under a Creative Commons Attribution 4.0 International License, which permits use, sharing, adaptation, distribution and reproduction in any medium or format, as long as you give appropriate credit to the original author(s) and the source, provide a link to the Creative Commons licence, and indicate if changes were made. The images or other third party material in this article are included in the article's Creative Commons licence, unless indicated otherwise in a credit line to the material. If material is not included in the article's Creative Commons licence and your intended use is not permitted by statutory regulation or exceeds the permitted use, you will need to obtain permission directly from the copyright holder. To view a copy of this licence, visit http://creativecommons.org/licenses/by/4.0/. 


\section{Background}

More pediatric patients are surviving open-heart surgery and the neurological complications seen in this patient group are decreasing each year. Rapid advances are also being made in pediatric heart surgery: There are new surgical techniques and neuroprotective methods, and surgeons are acquiring more experience with these patients. However, neurological complications are still an important cause of mortality and morbidity today, despite all these developments [1].

The incidence of neurological complications after openheart surgery in pediatric patients is known to differ from that of adults, as are the etiopathogenesis and risk factors of neurological complications [2]. The immaturity of pediatric patients' central nervous system, especially in the neonatal period and infancy, increases their susceptibility to neuronal damage and stroke. Neurological complications in this group are caused by microembolization, hypoxia, hypo- and hyperperfusion, white matter injury as a result of biochemical disorders, and neuronal damage as periventricular leukomalacia [3]. Cerebral thrombus and embolism play a role in the etiopathogenesis, with associated arterial ischemic stroke being a second mechanism in the other group. Preoperative neurological problems are also seen in children with congenital heart disease, regardless of surgical complications. It should be kept in mind that abnormal brain development, chromosomal and genetic anomalies, and sequelae such as thin and coarse motor deficits secondary to previous medical interventions, attention deficit hyperactivity disorder, and speech and language disorders may develop [4].

Prospective studies on patients who underwent openheart surgery using cardiopulmonary bypass (CPB) in the neonatal period found that their motor functions were weaker compared to the normal population even though their cognitive function was normal. This finding suggests that neurodevelopmental disorders may occur in later childhood periods in patients without cerebral damage [5].

Seizures are the most common symptom in pediatric patients who develop neurological complications after open-heart surgery. Postoperative seizures are associated with later development of severe cognitive sequelae in these patients, even though they are thought to be benign and due to postperfusion syndrome [2].

Clearly identifying the symptoms, prognostic factors, localization, and etiology of neurological complications will offer guidance in how to prevent them. Neuroprotective techniques and strategies, if applied carefully and correctly, can protect the patient from neurological sequelae that may be permanent [6]. In this retrospective study, we present the frequency, etiology, and results of neurological complications in the early postoperative period in patients undergoing pediatric cardiac surgery.

\section{Methods}

The patients were screened retrospectively. A total of 3849 patients who underwent pediatric heart surgery between June 2012 and May 2020 in our clinic were screened. One hundred and sixty-two patients with neurological symptoms lasting more than $24 \mathrm{~h}$, together with their neurological physical examination, cranial computed tomography (CT), and cranial magnetic resonance imaging (MRI) records were reviewed. Cranial imaging was performed by CT in patients who were considered to have experienced acute neurological events in our hospital, and diffusion MRI was performed in patients when deemed clinically necessary (e.g., in patients considered to have early ischemia). The patients' CT results were reported by the radiologist, all patients were followed up by specialist neurologists, and treatment was arranged according to the recommendation of their neurologist. The study included patients with neurological symptoms in the early postoperative period. Symptoms were classified as hemiparesis, seizure, confusion, and stupor. The affected localization and sides were noted in the patients' cranial CT records. The affected areas were recorded separately for patients affected in more than one region. The patients were divided into categories according to those who experienced a stroke, those who developed bleeding, and those whose CT results were clear or inconclusive despite having neurological symptoms.

The patients' medical information was obtained by scanning the hospital information system and archive files. Anamnesis, genetic syndromes, history of cardiopulmonary resuscitation (CPR), history of extracorporeal membrane oxygenation (ECMO), platelet values, intensive care, ventilator, and ward times were recorded from the patients' archive information. The preoperative neurological status of all patients was evaluated by a pediatrician and added to their files.

The operations that the patients underwent were classified according to RACHS scoring [7]. The patients' neurological examination results, symptoms, and neurological status were recorded daily by looking at the intensive care receipts made and recorded together with the physician, pediatrician, and neurologist attending the intensive care unit. $\mathrm{CPB}$ non-pulsatile flow rollers were provided with a pump, and a membrane oxygenator was used in all cases. The activated clotting time (ACT) of the patients with $\mathrm{CPB}$ was kept above $450 \mathrm{~s}$. All patients were routinely followed up with perioperative nearinfrared spectroscopy (NIRS). Heparin was used for anticoagulation. The patients' cannulations were performed selectively; the bicaval, aortic, and venous cannulation of 10 patients was performed atrially. Six patients underwent total circulatory arrest and deep hypothermia $\left(18-20{ }^{\circ} \mathrm{C}\right)$. 
The patients were extubated in the intensive care unit when adequate spontaneous breathing and airway reflexes were observed. Prior to any decision to extubate, each patient was evaluated for ability to perform simple orders, having an oropharyngeal temperature greater than $36.5{ }^{\circ} \mathrm{C}$, being hemodynamically stable, and not having uncontrolled arrhythmias. In addition, arterial blood gas analyses required $\mathrm{pH}$ to be over 7.30, $\mathrm{FiO} 2$ to be less than $50 \%, \mathrm{PaO} 2$ to be higher than $60 \mathrm{~mm} \mathrm{Hg}$, and $\mathrm{PaCO} 2$ to be lower than $45 \mathrm{~mm} \mathrm{Hg}$ (except for single ventricle patients). The decision to transfer a patient from the postoperative intensive care unit to the ward was made following assessment of cardiopulmonary stability by an intensive care specialist, pediatric cardiac surgeon, neurologist, and pediatrician.

Number Cruncher Statistical System (NCSS) 2007 software (Kaysville, UT, USA) was used for statistical analysis. Descriptive statistical methods (mean, standard deviation, median, frequency, ratio, minimum, and maximum) were used to evaluate the study data; the distribution of the data was evaluated using the Shapiro-Wilk test. The Mann-Whitney $U$ test was used to compare two groups that did not show a normal distribution of quantitative data. The $x^{2}$ was used to determine the relationship between qualitative data. Multiple logistic regression analysis was used to determine the effect of independent variables on the dependent variable. Significance was evaluated as $P<0.01$ and $P<0.05$.

\section{Results}

A total of 3849 patients were operated on between June 2012 and May 2020 in our pediatric heart surgery clinic, and 162 patients with neurological symptoms were included in the study. The rate of neurological complications in the early period was calculated as $4.2 \%$. The patients' ages ranged from 0-205 months, with a mean of $60.59 \pm 46.44$ months. Their weights ranged from 2$80 \mathrm{~kg}$, with a mean of $18.89 \pm 18.08 \mathrm{~kg}$. Tomography days ranged from $0-22$ days, with a mean of $4.35 \pm 3.22$ days. Intensive care unit time ranged from 4-175 days, with a mean of $34.18 \pm 31.21$ days. Ward times ranged from 0-34 days, with a mean of $8.22 \pm 7.14$ days. CPB time ranged from $30-215 \mathrm{~min}$, with a mean of $110.2 \pm$ $54.02 \mathrm{~min}$. Cross-clamp times ranged from 0-194 min, with a mean of $80.04 \pm 60.72 \mathrm{~min}$. Ventilator times ranged from 1-120 days, with a mean of $22.3 \pm 23.89$ days. Preoperative platelet values ranged from $86-663$ $10^{3} \mu \mathrm{L}$, with a mean of $306.73 \pm 104.7410^{3} \mu \mathrm{L}$ (Table 1 ).

Of the patients evaluated, 37 (22.8\%) had intracranial bleeding, 35 (21.6\%) had no radiological results, and 90 (55.6\%) developed stroke. Fifty-four patients (33.3\%) who developed neurological complications died and 108 (66.7\%) were discharged (Fig. 1). Thirty-four patients $(37.8 \%)$ in the stroke group died, as well as $15(40 \%)$ in
Table 1 Patients' demographic details

\begin{tabular}{lll}
\hline & Mean \pm SD & Min-max (median) \\
\hline Age (months) & $60.59 \pm 86.44$ & $0-205(15.5)$ \\
Weight (kg) & $18.89 \pm 18.08$ & $2-80(12.1)$ \\
Days of radiological imaging & $4.35 \pm 3.22$ & $0-22(3.5)$ \\
Intensive care unit time (days) & $34.18 \pm 31.21$ & $4-175(24)$ \\
Ward time (days) & $8.22 \pm 7.14$ & $0-34(8.5)$ \\
CPB (min) & $110.2 \pm 54.02$ & $30-215(120)$ \\
Cross-clamp (min) & $80.04 \pm 60.72$ & $0-194(83.5)$ \\
Ventilator time (days) & $22.3 \pm 23.89$ & $1-120(13.5)$ \\
Preoperative platelet $\left(10^{3} \mu \mathrm{L}\right)$ & $306.73 \pm 104.74$ & $86-663(298)$ \\
\hline
\end{tabular}

$C P B$ cardiopulmonary bypass

the intracranial bleeding group and $5(14.3 \%)$ in the no radiological results group (Fig. 2).

Eighty (49.4\%) of the patients were female and 82 (50.6\%) were male. According to the patients' RACHS scores, $9(5.6 \%)$ were 1 year old, $43(26.5 \%)$ were 2 years old, 57 (35.2\%) were 3 years old, 25 (15.4\%) were 4 years old, $18(11.1 \%)$ were 5 years old, and $10(6.2 \%)$ were 6 years old.

Patients with involvement of more than one region were taken separately within two regions. Ten (4.8\%) had cerebral involvement localizations in the brain stem, 56 (26.7\%) had frontal involvement, 58 (27.6\%) had parietal involvement, 58 (27.6\%) had temporal involvement, and 28 (13.3\%) had occipital involvement. Fifty-eight patients (35.8\%) had multiple region involvement and 35 (21.6\%) had no radiological results, while 69 patients (42.6\%) had singular CT lesions. Of the CT lesions, 51 patients (31.5\%) had a lesion on the left hemisphere, 38 (23.5\%) had bilateral lesions, 35 (21.6\%) had CT results, and $38(23.5 \%)$ had a lesion on the right hemisphere.

Of the patients who experienced symptoms after surgery, 69 (42.6\%) had seizures, 17 (10.5\%) had confusion, 39 (24.1\%) had stupor, and 37 (22.8\%) had hemiparesis (Table 2). Regarding the interventions performed on the patients, 97 (61\%) without CPR, 62 (39\%) underwent CPR, 141 (87\%) underwent ECMO, and 21 (13\%) underwent CPR. Four patients $(2.5 \%)$ had Down syndrome and 158 (97.5\%) did not (see Table 2).

No statistically significant differences were found regarding the patients' age, weight, $\mathrm{CPB}$, or cross-clamp values $(P>0.05)$. CT scans showed a statistically significant difference in the group without stroke/intracranial bleeding/no radiological results $(P=0.001 ; P<0.01)$. The fact that the tomography days of the group with no radiological results were low was found to be statistically significant compared to those of the stroke and intracranial bleeding groups $(P=0.001 ; P<0.01)$. There was a statistically significant difference in the length of time spent in the intensive care unit in the stroke/intracranial 


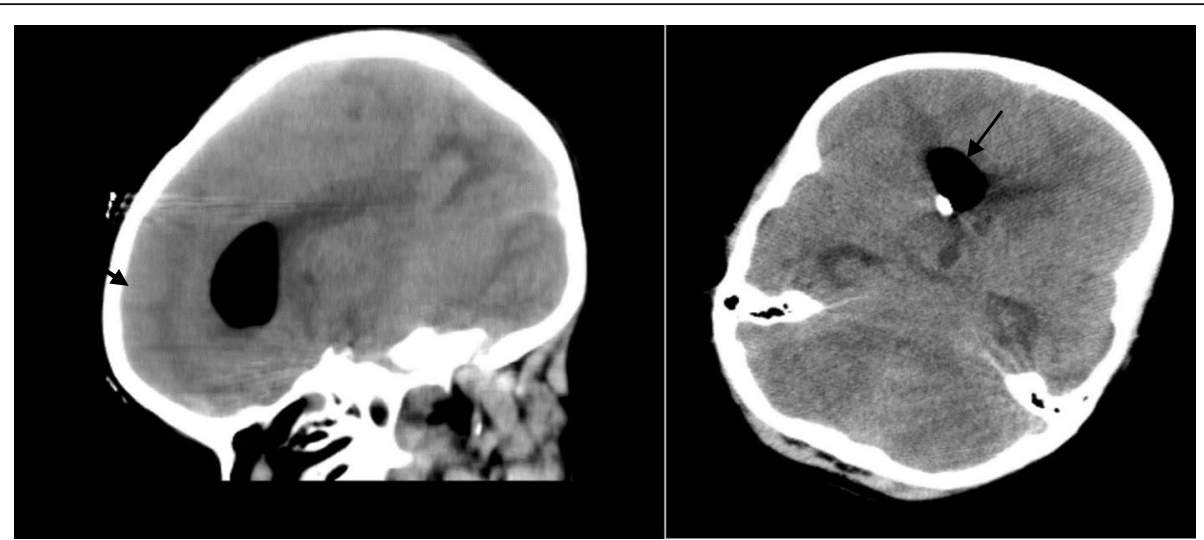

Fig. 1 CT images of a 4-year-old patient who underwent Fontan surgery in single ventricular physiology after postoperative bleeding in the left temporal lobe (indicated by the black arrow). Extensive intracranial bleeding developed in the patient's left temporal region on the fourth postoperative day after Fontan surgery. A drainage set was inserted by neurosurgery to relieve signs of compression

bleeding/no radiological results group $(P=0.001 ; P<$ 0.01). The intensive care unit time of the group with no radiological results was low, which was found to be statistically significant compared to those of the stroke and bleeding groups $(P=0.001 ; P<0.01)$. Stroke/intracranial bleeding/no radiological results showed a statistically significant difference according to the group $(P=0.048$; $P<0.05)$. The ward time of the group with no radiological results was high, which was found to be statistically significant compared to those of the stroke and bleeding groups $(P=0.001 ; P<0.01)$. There were statistically significant differences in ventilator times for the stroke/intracranial bleeding/no radiological results group $(P=0.001 ; P<0.01)$. The ventilator time for the group with no radiological results was low, which was found to be statistically significant compared to those of the stroke and bleeding groups $(P=0.001 ; P<0.01)$. There were no statistically significant differences in preoperative platelet values among the patients who did not experience complications $(P>0.05$; see Table 3$)$.

A statistically significant relationship was found between stroke/intracranial bleeding/no radiological results and life status $(P=0.025 ; P<0.05)$. The lowest mortality was found in the no radiological results group, while the bleeding group experienced the highest mortality rate. No statistically significant relationship was found between the stroke/intracranial bleeding/no radiological results group and sex $(P>0.05)$ or RACHS classification $(P>0.05)$. A statistically significant relationship was found between stroke/intracranial bleeding/ no radiological results group in terms of finding single or multiple lesions $(P=0.001 ; P<0.01)$, lesion side $(P=0.001$; $P<0.01)$, and symptom $(P=0.001 ; P<0.01)$. No statistically significant relationship was found between stroke/intracranial bleeding/no radiological results group and CPR $(P>$

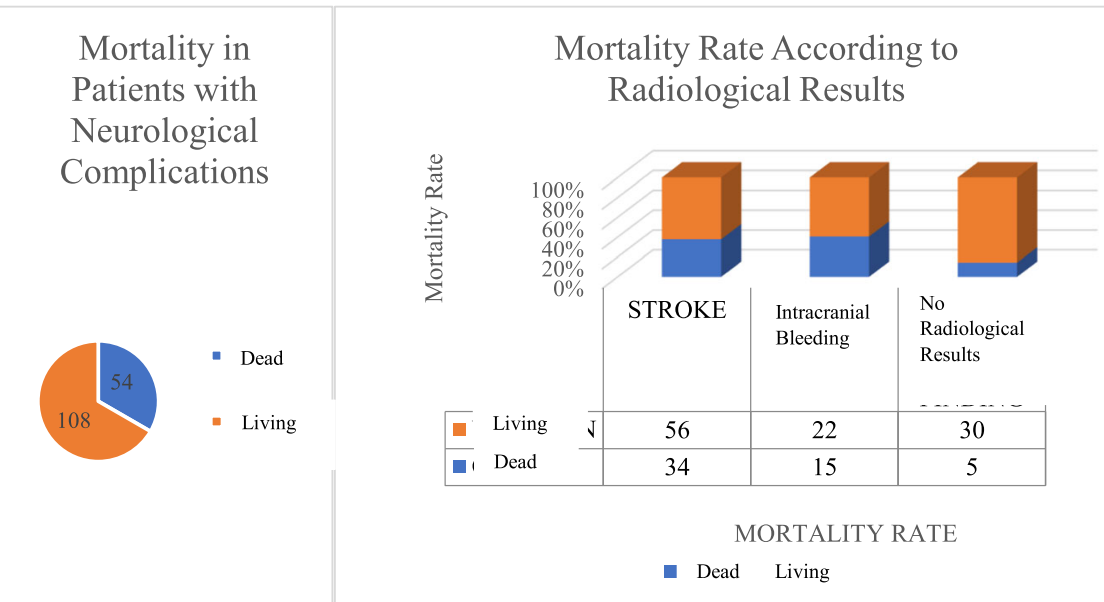

Fig. 2 The mortality rates of patients after classification according to their radiological results 
Table 2 The relationship between life status and measurements

\begin{tabular}{|c|c|c|c|c|}
\hline \multirow[t]{2}{*}{ Patient characteristics } & & \multicolumn{2}{|l|}{ Life status } & \multirow[t]{2}{*}{$P$} \\
\hline & & Dead & Living & \\
\hline \multirow[t]{2}{*}{ Sex } & Female & $29(53.7 \%)$ & $51(47.2 \%)$ & 0.437 \\
\hline & Male & $25(46.3 \%)$ & $57(52.8 \%)$ & \\
\hline \multirow[t]{6}{*}{ RACHS score } & 1 & $1(1.9 \%)$ & $8(7.4 \%)$ & 0.609 \\
\hline & 2 & $13(24.1 \%)$ & $30(27.8 \%)$ & \\
\hline & 3 & $20(37 \%)$ & 37 (34.3\%) & \\
\hline & 4 & $9(16.7 \%)$ & $16(14.8 \%)$ & \\
\hline & 5 & $6(11.1 \%)$ & $12(11.1 \%)$ & \\
\hline & 6 & $5(9.3 \%)$ & $5(4.6 \%)$ & \\
\hline \multirow[t]{3}{*}{ Lesion distribution } & Single & 19 (35.2\%) & $50(46.3 \%)$ & $0.001^{* *}$ \\
\hline & Multiple & $30(55.6 \%)$ & $28(25.9 \%)$ & \\
\hline & No radiological results & $5(9.3 \%)$ & $30(27.8 \%)$ & \\
\hline \multirow[t]{4}{*}{ Lesion side } & Right & $13(24.1 \%)$ & 25 (23.1\%) & $0.003^{* *}$ \\
\hline & Left & $15(27.8 \%)$ & $36(33.3 \%)$ & \\
\hline & Bilateral & $21(38.9 \%)$ & $17(15.7 \%)$ & \\
\hline & No radiological results & $5(9.3 \%)$ & $30(27.8 \%)$ & \\
\hline \multirow[t]{4}{*}{ Postoperative symptom } & Hemiparesis & $7(13 \%)$ & $30(27.8 \%)$ & $0.001^{* *}$ \\
\hline & Seizure & $10(18.5 \%)$ & $59(54.6 \%)$ & \\
\hline & Confusion & $2(3.7 \%)$ & 15 (13.9\%) & \\
\hline & Stupor & $35(64.8 \%)$ & $4(3.7 \%)$ & \\
\hline \multirow[t]{2}{*}{ CPR use } & None & $3(5.8 \%)$ & 94 (87.9\%) & $0.001^{* *}$ \\
\hline & Yes & 49 (94.2\%) & $13(12.1 \%)$ & \\
\hline \multirow[t]{2}{*}{ ECMO use } & Yes & $16(29.6 \%)$ & $5(4.6 \%)$ & $0.001^{* *}$ \\
\hline & None & $38(70.4 \%)$ & $103(95.4 \%)$ & \\
\hline \multirow[t]{2}{*}{ Additional syndrome } & Down & $1(1.9 \%)$ & $3(2.8 \%)$ & 0.593 \\
\hline & None & $53(98.1 \%)$ & $105(97.2 \%)$ & \\
\hline \multirow[t]{5}{*}{ Cerebral localization } & Brainstem & $6(60 \%)$ & $4(40 \%)$ & 0.079 \\
\hline & Frontal & 17 (30.4\%) & 39 (69.6\%) & \\
\hline & Parietal & $25(43.1 \%)$ & 33 (56.9\%) & \\
\hline & Temporal & $21(36.2 \%)$ & 37 (63.8\%) & \\
\hline & Occipital & $15(53.6 \%)$ & 13 (46.4\%) & \\
\hline
\end{tabular}

$X^{2}: * * P<0.01$

$0.05)$, ECMO $(P>0.05)$, syndrome $(P>0.05)$, or cerebral localization $(P>0.05)$.

Age value, tomography days, weight value, $\mathrm{CPB}$ time, and cross-clamp time were not found to show statistically significant differences according to life status after a neurological event $(P>0.05)$. The fact that the dead group had a high number of days in intensive care was found to be statistically significant compared to the living group $(P=0.002 ; P<0.01)$. The fact that the dead group had high ventilator times compared to the living group was found to be statistically significant $(P=0.001$; $P<0.01)$. Preoperative platelet values did not show a statistically significant difference according to life status $(P>0.05)$.
No statistically significant relationship was found between life status and sex, RACHS scoring, and localization $(P>0.05)$. There was a statistically significant relationship between life status and lesion distribution (single-multiple), lesion side, symptom, CPR, and ECMO history $(P<0.01)$.

The simple logistic regression analysis was found to be statistically significant in determining the effect of the situation without $\mathrm{CT}$ results on life status when the data presented in Table 4 was examined $\left(X^{2}=8.144, P<\right.$ 0.001 ). A positive and weak significant relationship was observed between the no radiological results variable and life status $(R=0.068, P<0.001)$. The no radiological results independent variable in the model explained 
Table 3 Comparison of scales according to the stroke/intracranial bleeding/no radiological results groups

\begin{tabular}{|c|c|c|c|c|c|}
\hline & & $n$ & Mean \pm SD & Min-max (median) & $P$ \\
\hline \multirow[t]{3}{*}{ Age (months) } & Stroke & 90 & $67.51 \pm 88.49$ & $0-444(15.5)$ & 0.101 \\
\hline & Intracranial bleeding & 37 & $40.57 \pm 75.49$ & $0-408(12)$ & \\
\hline & No radiological results & 35 & $63.94 \pm 90.95$ & $1-408(24)$ & \\
\hline \multirow[t]{3}{*}{ Weight (kg) } & Stroke & 90 & $20.65 \pm 19.5$ & $3-80(12)$ & 0.057 \\
\hline & Intracranial bleeding & 37 & $13.46 \pm 14.34$ & 2-78 (11) & \\
\hline & No radiological results & 35 & $20.09 \pm 17.12$ & $3.1-61.5(13.1)$ & \\
\hline \multirow[t]{3}{*}{ Days of radiological imaging } & Stroke & 90 & $4.77 \pm 3.45$ & $0-22(4)$ & $0.001^{* *}$ \\
\hline & Intracranial bleeding & 37 & $4.57 \pm 3.24$ & $1-16(4)$ & \\
\hline & No radiological results & 35 & $3.03 \pm 2.12$ & $0-12(2)$ & \\
\hline \multirow[t]{3}{*}{ Days in intensive care } & Stroke & 90 & $38.46 \pm 34.58$ & $5-175(24)$ & $0.001^{* *}$ \\
\hline & Intracranial bleeding & 37 & $36.05 \pm 28.51$ & $4-148(31)$ & \\
\hline & No radiological results & 35 & $21.2 \pm 19.89$ & $4-84(14)$ & \\
\hline \multirow[t]{3}{*}{ Ward time (days) } & Stroke & 90 & $7.68 \pm 7.16$ & $0-34(8.5)$ & $0.048^{*}$ \\
\hline & Intracranial bleeding & 37 & $7.19 \pm 7.36$ & $0-27(7)$ & \\
\hline & No radiological results & 35 & $10.71 \pm 6.47$ & $0-24(11)$ & \\
\hline \multirow[t]{3}{*}{ CPB time (min) } & Stroke & 90 & $108.57 \pm 51.65$ & $30-215(114)$ & 0.792 \\
\hline & Intracranial bleeding & 37 & $112.08 \pm 66.51$ & $30-215(124)$ & \\
\hline & No radiological results & 35 & $112.4 \pm 46.23$ & 30-194 (125) & \\
\hline \multirow[t]{3}{*}{ Cross-clamp time (min) } & Stroke & 90 & $72.69 \pm 59.57$ & 0-184 (74) & 0.239 \\
\hline & Intracranial bleeding & 37 & $88.65 \pm 69.58$ & 0-194 (114) & \\
\hline & No radiological results & 35 & $89.83 \pm 52.14$ & 0-181 (109) & \\
\hline \multirow[t]{3}{*}{ Ventilator time (days) } & Stroke & 90 & $26.61 \pm 27.28$ & $1-120(15.5)$ & $0.001^{* *}$ \\
\hline & Intracranial bleeding & 37 & $22.62 \pm 18.46$ & $3-78(16)$ & \\
\hline & No radiological results & 35 & $10.86 \pm 14.49$ & 2-68 (4) & \\
\hline \multirow[t]{3}{*}{ Preoperative platelets $\left(10^{3} \mu \mathrm{L}\right)$} & Stroke & 90 & $313.62 \pm 108.6$ & 116-663 (299) & 0.699 \\
\hline & Intracranial bleeding & 37 & $290.03 \pm 113.44$ & $86-545(296)$ & \\
\hline & No radiological results & 35 & $306.66 \pm 83.78$ & $176-518$ (295) & \\
\hline
\end{tabular}

Kruskal-Wallis test: ${ }^{*} P<0.05 ;{ }^{*} P<0.01$

$C P B$ cardiopulmonary bypass

Table 4 Logistic regression analysis results for predicting life status with independent variables

\begin{tabular}{|c|c|c|c|c|c|c|c|c|c|c|}
\hline \multirow[b]{2}{*}{ Variables } & \multicolumn{5}{|c|}{ Univariate } & \multicolumn{5}{|c|}{ Multivariate } \\
\hline & $\bar{B}$ & S. error & $\beta$ & Wald & $P$ & $\bar{B}$ & S. error & $B$ & Wald & $P$ \\
\hline No radiological results & 1.327 & 0.516 & 3.769 & 6.605 & $0.001^{* *}$ & & & & & \\
\hline Distribution-multiple & -1.273 & 0.351 & 0.280 & 13.151 & $0.001^{* *}$ & & & & & \\
\hline Side_-bilateral & -1.226 & 0.384 & 0.294 & 10.169 & $0.001^{* *}$ & & & & & \\
\hline \multicolumn{11}{|l|}{ Symptoms } \\
\hline Hemiparesis & 0.949 & 0.459 & 2.582 & 4.280 & $0.001^{* *}$ & 3.163 & 1.196 & 23.636 & 6.994 & $0.001^{* *}$ \\
\hline Seizure & 1.667 & 0.400 & 5.298 & 17.366 & $0.001^{* *}$ & 3.876 & 1.179 & 48.221 & 10.816 & $0.001^{* *}$ \\
\hline Confusion & - & - & - & - & - & 4.007 & 1.619 & 54.964 & 6.124 & $0.001^{* *}$ \\
\hline Stupor & -3.869 & 0.584 & 0.021 & 43.921 & $0.001^{* *}$ & & & & & \\
\hline CPR & 4.772 & 0.664 & 0.008 & 51.592 & $0.001^{* *}$ & 4.893 & 0.842 & 85.26 & 26.088 & $0.001^{* *}$ \\
\hline
\end{tabular}

$$
\begin{aligned}
& { }^{* *} P<0.01 \\
& { }^{*} P<0.05
\end{aligned}
$$


$0.06 \%$ of the total variance in life status $(P<0.01)$ and had a positive and significant effect on life status when the regression coefficients were examined $(\beta=3.769, P<$ $0.001)$. The simple logistic regression analysis was found to be statistically significant in determining the effect of the distribution-multiple variable on life status $\left(\chi^{2}=\right.$ 13.532, $P<0.001)$, which had a positive and weak significant relationship $(R=0.080 ; P<0.001)$. The distribution-multiple independent variable in the model explained $0.08 \%$ of the total variance in life status $(P<$ 0.01 ) and had a positive and significant effect on life status when the regression coefficients were examined $(\beta=$ $0.280, P<0.001$ ).

The simple logistic regression analysis was found to be statistically significant in determining the effect of the bilateral lesion side on life status when the data presented in Table 5 were examined $\left(\chi^{2}=10.289, P<\right.$ $0.001)$. A positive and weak significant relationship was observed between bilateral involvement and life status $(R=0.062 ; P<0.001)$. The side-bilateral independent variable in the model explained $0.06 \%$ of the total variance in life status $(P<0.01)$, and the two were found to have a positive and significant effect on life status when the regression coefficients were examined $(\beta=0.294, P<0.001)$. The simple logistic regression analysis was found to be statistically significant in determining the effect of hemiparesis on life status $\left(\chi^{2}=4.819, P<0.001\right)$. A positive and weak significant relationship was observed between life status and developing hemiparesis symptoms $(R=0.029 ; P<$ 0.001 ). The hemiparesis independent variable in the model explained $0.03 \%$ of the total variance in life status $(P<0.01)$ and had a positive and significant effect on life status when the regression coefficients were examined $(\beta=2.582, P<0.001)$.

The simple logistic regression analysis was found to be statistically significant in determining the effect of seizure on life status in our regression analysis $\left(\chi^{2}=20.469\right.$,
$P<0.001)$. A positive and weak significant relationship was observed between seizure and life status $(R=0.119$; $P<0.001)$. The seizure independent variable in the model explained $0.12 \%$ of the total variance in life status $(P<0.01)$, and had a positive and significant effect on life status when the regression coefficients were examined $(\beta=5.298, P<0.001)$. The simple logistic regression analysis was found to be statistically significant in determining the effect of stupor on life status $\left(\chi^{2}=74.562, P<\right.$ 0.001 ), and a positive and weak significant relationship was observed between them $(R=0.369 ; P<0.001)$. The insomnia independent variable in the model explained $0.37 \%$ of the total variance in life status $(P<0.01)$. The stupor variable had a positive and significant effect on life status when the regression coefficients were examined $(\beta=0.021, P<0.001)$.

The simple logistic regression analysis was found to be statistically significant in determining the effect of CPR on life status $\left(X^{2}=110.556, P<0.001\right)$, and a positive and moderate significant relationship was observed between the two $(R=0.501 ; P<0.001)$. The CPR independent variable in the model explained $50 \%$ of the total variance in life status $(P<0.01)$ and had a positive and significant effect on life status when the regression coefficients were examined $(\beta=85.26, P<0.001)$.

The multiple logistic regression analysis was found to be statistically significant in determining the effect of the independent variables on life status $\left(\chi^{2}=\right.$ 141.399, $P<0.001)$. A positive and moderate significant relationship was observed between independent variables and life status $(R=0.589, P<0.001)$, and the independent variables in the model explained $58.9 \%$ of the total variance in life status.

Hemiparesis $(\beta=23.636, \quad P<0.001), \quad$ seizure $\quad(\beta=$ 48.221, $P<0.001)$, confusion $(\beta=54.964, P<0.001)$, and CRP $(\beta=85.26, P<0.001)$ had positive and statistically significant effects on mortality when the regression coefficients were examined.

Table $\mathbf{5}$ Logistic regression analysis results for prediction of life status with independent variables

\begin{tabular}{|c|c|c|c|c|c|c|c|c|c|c|c|}
\hline \multirow[t]{2}{*}{ Model } & \multirow[t]{2}{*}{ Variables } & \multicolumn{5}{|c|}{ Univariate } & \multicolumn{5}{|c|}{ Multivariate } \\
\hline & & B & S. error & $\beta$ & Wald & $P$ & B & S. error & B & Wald & $P$ \\
\hline \multirow[t]{9}{*}{1} & No radiological results & 1.327 & 0.516 & 3.769 & 6.605 & $0.001^{* *}$ & & & & & \\
\hline & Distribution—multiple & -1.273 & 0.351 & 0.280 & 13.151 & $0.001^{* *}$ & & & & & \\
\hline & Side_-bilateral & -1.226 & 0.384 & 0.294 & 10.169 & $0.001^{* *}$ & & & & & \\
\hline & Symptoms & & & & & & & & & & \\
\hline & Hemiparesis & 0.949 & 0.459 & 2.582 & 4.280 & $0.001^{* *}$ & 3.163 & 1.196 & 23.636 & 6.994 & $0.001^{* *}$ \\
\hline & Seizure & 1.667 & 0.400 & 5.298 & 17.366 & $0.001^{* *}$ & 3.876 & 1.179 & 48.221 & 10.816 & $0.001^{* *}$ \\
\hline & Confusion & - & - & - & - & - & 4.007 & 1.619 & 54.964 & 6.124 & $0.001^{* *}$ \\
\hline & Stupor & -3.869 & 0.584 & 0.021 & 43.921 & $0.001^{* *}$ & & & & & \\
\hline & CPR & 4.772 & 0.664 & 0.008 & 51.592 & $0.001 * *$ & 4.893 & 0.842 & 85.26 & 26.088 & $0.001^{* *}$ \\
\hline
\end{tabular}




\section{Discussion}

Neurological complications after pediatric heart surgery are still an important cause of mortality and morbidity today. The treatment of neurological complications is usually palliative; the main goal is to prevent them using neuroprotective methods, as there is no sequelae-free treatment for the majority of patients [8]. In our study, we investigated the prognosis of patients who developed neurological complications in the early postoperative period and the factors affecting their prognoses.

The risk of stroke is low, as atherosclerosis is less common in the pediatric population than in the corresponding adult population. The risk of stroke in the adult group is reported to be $6 \%$ in the literature [9], while among the pediatric population it is $0.54 \%$ according to Domi et al. [1]. The risk of developing neurological events was found to be $4.2 \%$; in our study, $55.6 \%$ of the patients we evaluated had a stroke, although the rate of stroke development among all patients who underwent surgery was $2.3 \%$.

Although there are rarely clinical signs of cranial diffuse radiological involvement in the pediatric population, the duration of neurological morbidity in these patients is much longer than that of adults $[10,11]$. We included symptomatic patients in our study: patients who did not develop neurological symptoms but had imaging results constitute a limitation of our study.

Jafri et al. reported that $35(1.75 \%)$ of the 2000 pediatric cardiac surgery patients they evaluated developed acute neurological complications, and 28 of those 35 patients (80\%) presented clinical signs of seizure [4]. Of the 3849 patients who underwent surgery, 162 had neurological complications in the early period, comprising a rate of $4.2 \%$ in our patient group; $42.6 \%$ of these 162 patients $(n=69)$ had seizures, $10.5 \%(n=17)$ had confusion, $24.1 \% \quad(n=39)$ had stupor symptoms, and $22.8 \%(n=37)$ demonstrated symptoms of hemiparesis. One of the reasons for the high number of stroke patients may be that the mean age of our patients was older.

Trittenwein et al. argued that the effect of $\mathrm{CPB}$ time on neurological damage in the early postoperative period was statistically insignificant and that being above 100 $\mathrm{mg} / \mathrm{dL}$ at lactate levels with postoperative acidosis was the cause of $30 \%$ of cerebral damage symptoms [12]. We found in our study that age, weight, $\mathrm{CPB}$, and crossclamp time had no statistically significant effect on mortality in patients who experienced a neurological event. Of the patients who died, $64.8 \%$ had stupor, $3.7 \%$ had confusion, $18.5 \%$ had seizures, and $13 \%$ had hemiparesis. We found that presenting with neurological complaints soon after surgery was a statistically significant predictor of mortality.
Implanting cardiac shunts (ASD, VSD) in congenital heart patients may cause paradoxical embolisms, and it is known that high hematocrit values create a predisposition to coagulopathy in the majority of these patients. Antiaggregant and anticoagulant drugs used in the postoperative period increase the risk of bleeding. However, ischemic strokes were reported to be more common than intracranial bleeding in this cohort, despite the use of antiaggregant and anticoagulant medications [13]. The rate of ischemic stroke was higher in patients who underwent CT imaging compared to the others in our study. This may be due to increased myeloid and thrombocyte blood cell series secondary to coagulopathies and hypoxia secondary to genetic syndromes, which are common in these patient groups.

Werho et al. reported that patients undergoing pediatric cardiac surgery connected to ECMO had the highest risk of stroke and other neurological complications [14]. Twenty-one of the patients we evaluated developed neurological complications during ECMO, and mortality was calculated as $29.6 \%$ in the ECMO group and $4.6 \%$ in the non-ECMO group in our study. Of these, 13 (62\%) did not have ischemia, 7 (33.3\%) did not have bleeding, and 1 (4.7\%) did not have radiological imaging results. We think that blood-shaped element destruction and bleeding may occur following the administration of anticoagulant drugs, while ischemic events are the result of inflammatory reactions and associated increased coagulation caused by lines and solutions used in ECMO circulation.

In their study on strokes after pediatric cardiac intervention, Henzi et al. reported that patients who developed neurological complications showed symptoms after an average of 4 days and were diagnosed after an average of 2 days; they stated that hypotension, prosthetic heart material, right-to-left shunt, arrhythmias, low heart rate, and infections are risk factors [15]. In our study, the diagnosis time was 4.7 days in the stroke group, 4.5 days in the bleeding group, and 3 days in the group with no $\mathrm{CT}$ results, which is similar to the results reported by Henzi et al. [15].

Madhok et al. argued that the increased need for vasoactive inotropes increased pro-inflammatory cytokines with decreased heart rate and increased morbidity by reducing cerebral perfusion pressure and oxygenation [16]. We did not find a statistically significant difference between the etiology (ischemia, bleeding, etc.) and mortality of patients who developed neurological complications when we classified the patients according to their RACHS scores in our study.

It is necessary to monitor the effects of coronary bypass on the central nervous system in order to prevent cerebral damage associated with cardiac surgery. NIRS, a noninvasive method in $\mathrm{CPB}$ management, especially 
during TSA and regional low-flow perfusion, is useful in preventing neurological complications after pediatric heart surgery [17]. We routinely use NIRS monitoring in our own surgical practice.

Agha et al. found that CT and MRI results and myocardial contraction power were correlated with each other, but they did not find a statistically significant correlation with the length of intensive care stay [6]. We found a statistically significant difference between the duration of intensive care when we separated the patients into ischemic, bleeding, and no radiological results categories, in both the dead and the living groups in our study. The longest intensive care period was 38.46 days in the ischemia group, followed by bleeding (36.05 days) and no radiological results (21.2 days).

Requiring ECMO and CPR in the postoperative period increases the risk of neurological complications, and $13 \%$ of neurological complications occur after ECMO intervention after $\mathrm{CPR}$, a procedure that combines the two interventions, according to Extracorporeal Life Support Organization records [18]. Mortality was found to be statistically significantly higher in the CPR and ECMO groups of patients with neurological complications in our study. Ischemic strokes are more common in both groups than in the general population, although there was no statistically significant relationship when the CT results of the ECMO and CPR groups were examined.

Andropoulos et al. investigated the factors affecting brain damage after neonatal heart surgery and presented their own treatment and prevention strategies [19]. They argued that brain damage revealed in postoperative MRI examinations of this patient group may be prenatal, postnatal, or preoperative, and emphasized the importance of detecting, diagnosing, preventing, and early treatment of brain damage in the neonatal period to optimize neurodevelopmental outcomes [19]. In our study, we found that age and patient weight had no statistically significant effect on mortality in patients who developed neurological damage. The mean age and weight of the bleeding group were found to be lower, which is thought to be due to the immature coagulation system causing a tendency to bleed in the neonatal period, although no statistically significant results were found when the ages and weights of the bleeding and stroke groups were compared.

The rate of acute neurological complications was reported to be $2-3 \%$ in the postoperative period. However, it varied greatly depending on age and modality in the postoperative period, and neurological complications have been detected in up to $50 \%$ even if postoperative imaging methods (MRI, EEG, CT) used on nonsymptomatic patients revealed no clinical signs. Our knowledge of the clinical significance of these signs in asymptomatic patients is neither clear nor sufficient [20-24]. It is currently not possible to detect subclinical cases in such patients, even though the incidence of postoperative neurological complications was $4.2 \%$ in our study Gunn et al. found that the motor, language, and cognitive scores of patients who developed neurological complications after pediatric heart surgery were lower than the rest of the population in post-discharge follow-ups [2]. In our study, we found mortality rate to be $33.3 \%$; this result can be interpreted as indicating that the remaining $66.7 \%$ have a high morbidity rate in the future, according to Gunn et al. [2].

In our study, the need for prolonged ventilation and prolonged intensive care were found to be statistically significant predictors of mortality in patients with neurological complications. The highest mortality rate $(60 \%)$ was found to affect patients with brainstem involvement, even though there was no statistically significant difference between the localization of neurological sequelae and mortality in our study.

\section{Conclusions}

Current treatment modalities, and mortality and morbidity are very high in patients with neurological complications. The number of studies on neurological complications after pediatric heart surgery in the literature remains insufficient. We think that our study will contribute to a more detailed discussion of the issue. As responses to neurological events in and treatment for this age group may differ from those of adult patients, primary prevention methods should be the main approach to combating neurological complications; these patients' formation mechanisms should be carefully monitored, and more preventive treatment strategies must be developed.

\section{Limitations}

This is a single-center, retrospective study. Postoperative routine cranial imaging is not performed in our hospital. Cranial CT scans were performed for all patients with symptoms upon admittance. Diffusion MRI, which provided better images of ischemic status in the early period, was applied to all patients upon recommendation by the neurology specialist. Failure to perform imaging on patients without neurological symptoms constitutes the primary limitation of this study.

\section{Abbreviations \\ ACT: Activated clotting time; CPB: Cardiopulmonary bypass; \\ CPR: Cardiopulmonary resuscitation; CT: Computed tomography; ECMO: Extracorporeal membrane oxygenation; NIRS: Near-infrared spectroscopy}

Acknowledgements

Not applicable. 


\section{Authors' contributions}

Study design by EA, KAK, and ÖFŞ; Data collection by EA, CA, FY, AAY, and UU; Writing by EA, FY, and KAK; Supervising by HC, NÇ, and ET; Final approval by all authors. All authors have read and approved the manuscript.

\section{Funding}

No funding was obtained for this study.

Availability of data and materials

Data sharing is not applicable to this article as no new data were created or analyzed in this study.

\section{Declarations}

\section{Ethics approval and consent to participate}

The study protocol was approved by the hospital management. The study is retrospective, and consent to participate was waived by the IRB. The committee's reference number is not applicable. The study was conducted in accordance with the principles of the Declaration of Helsinki.

\section{Consent for publication}

Specific research consent was not obtained and waived. Before surgery, written informed consent to publish this information was obtained from study participants next of kin and/or parent/legal guardian.

\section{Competing interests}

The authors declare that they have no competing interests.

\section{Author details}

'Pediatric Cardiovascular Surgery Department, Kartal Kosuyolu High Education and Training Hospital, Cevizli, 2, Denizer Caddesi, Cevizli Kavşağı, 34865 Kartal, Istanbul, Turkey. ${ }^{2}$ Anesthesia and Reanimation Department Kartal Kosuyolu High Education and Training Hospital Istanbul Turkey

Received: 21 June 2021 Accepted: 3 September 2021

Published online: 18 September 2021

\section{References}

1. Domi T, Edgell DS, McCrindle BW, Williams WG, Chan AK, MacGregor DL et al (2008) Frequency, predictors, and neurologic outcomes of vasoocclusive strokes associated with cardiac surgery in children. Pediatrics 122(6):1292-1298. https://doi.org/10.1542/peds.2007-1459

2. Gunn JK, Beca J, Hunt RW, Goldsworthy M, Brizard CP, Finucane K, Donath S, Shekerdemian LS (2016) Perioperative risk factors for impaired neurodevelopment after cardiac surgery in early infancy. Arch Dis Child 101(11):1010-1016. https://doi.org/10.1136/archdischild-2015-309449

3. Avila-Alvarez A, Gonzalez-Rivera I, Ferrer-Barba A, Portela-Torron F, GonzalezGarcia E, Fernandez-Trisac JL, Ramil-Fraga C (2012) Complicaciones neurológicas en el postoperatorio inmediato de cirugía cardiaca: todavía un largo camino por recorrer [Acute neurological complications after pediatric cardiac surgery: still a long way to go]. An Pediatr (Barc) 76(4):192-198. Spanish. https://doi.org/10.1016/j.anpedi.2011.07.018

4. Jafri SK, Ehsan L, Abbas Q, Ali F, Chand P, UI HA (2017) Frequency and outcome of acute neurologic complications after congenital heart disease surgery. J Pediatr Neurosci 12(4):328-331. https://doi.org/10.4103/jpn.JPN_87_17

5. Menache CC, du Plessis AJ, Wessel DL, Jonas RA, Newburger JW (2002) Current incidence of acute neurologic complications after open-heart operations in children. Ann Thorac Surg 73(6):1752-1758. https://doi.org/1 0.1016/s0003-4975(02)03534-8

6. Agha H, Hussien MM, Girgis MY, Afify OGE, Haroun M (2021) Neurological sequelae following pediatric cardiac interventions. Open Access Maced J Med Sci 9(B):137-143. https://doi.org/10.3889/oamjms.2021.5581

7. Simsic JM, Cuadrado A, Kirshbom PM, Kanter KR (2006) Risk adjustment for congenital heart surgery (RACHS): is it useful in a single-center series of newborns as a predictor of outcome in a high-risk population? Congenit Heart Dis 1(4):148-151. https://doi.org/10.1111/j.1747-0803.2006.00026.x

8. Hocker S, Wijdicks EF, Biller J (2014) Neurologic complications of cardiac surgery and interventional cardiology. Handb Clin Neurol 119:193-208. https://doi.org/10.1016/B978-0-7020-4086-3.00014-X
9. Roach GW, Kanchuger M, Mangano CM, Newman M, Nussmeier N, Wolman R, Aggarwal A, Marschall K, Graham SH, Ley C, Ozanne G, Mangano DT, Herskowitz A, Katseva V, Sears R (1996) Adverse cerebral outcomes after coronary bypass surgery. N Engl J Med 335(25):1857-1863. https://doi.org/1 0.1056/NEJM199612193352501

10. McConnell JR, Fleming WH, Chu WK, Hahn FJ, Sarafian LB, Hofshire PJ et al (1990) Magnetic resonance imaging of the brain in infants and children before and after cardiac surgery: a prospective study. Am J Dis Child 144(3): 374-378. https://doi.org/10.1001/archpedi.1990.02150270124041

11. Muraoka R, Yokota M, Aoshima M, Kyoku I, Nomoto S, Kobayashi A, Nakano H, Ueda K, Saito A, Hojo H (1981) Subclinical changes in brain morphology following cardiac operations as reflected by computed tomographic scans of the brain. J Thorac Cardiovasc Surg 81(3):364-369. https://doi.org/10.101 6/S0022-5223(19)37599-3

12. Trittenwein G, Nardi A, Pansi H, Golej J, Burda G, Hermon M, Boigner $H$, Wollenek $G$, Verein zur Durchführung wissenschaftlichter Forschung auf dem Gebeit der Neonatologie und Pädiatrischen Intensivmedizin (2003) Verein zur durchführung wissenschaftlichter forschung auf dem gebeit der neonatologie und pädiatrischen intensivmedizin [Early postoperative prediction of cerebral damage after pediatric cardiac surgery]. Ann Thorac Surg 76(2):576-580. https://doi.org/10.1016/s0003-4975(03)00468-5

13. Fox CK, Sidney S, Fullerton HJ (2015) Community-based case-control study of childhood stroke risk associated with congenital heart disease. Stroke 46(2):336-340. https://doi.org/10.1161/STROKEAHA.114.007218

14. Werho DK, Pasquali SK, Yu S, Donohue J, Annich GM, Thiagarajan RR, HirschRomano JC, Gaies M, ELSO Member Centers (2015) Epidemiology of stroke in pediatric cardiac surgical patients supported with extracorporeal membrane oxygenation. Ann Thorac Surg 100(5):1751-1757. https://doi. org/10.1016/j.athoracsur.2015.06.020

15. Henzi BC, Brotschi B, Balmer C, Hennig B, Rimensberger P, Perez MH, Pfammatter JP, Beghetti M, Sekarski N, Datta AN, Fluss J, Faignart N, Hackenberg A, Regényi M, Steinlin M, Hug MI (2020) Risk factors for postprocedural arterial ischemic stroke in children with cardiac disease. Stroke 51(9):e242-e245. https://doi.org/10.1161/STROKEAHA.120.029447

16. Madhok AB, Ojamaa K, Haridas V, Parnell VA, Pahwa S, Chowdhury D et al (2006) Cytokine response in children undergoing surgery for congenital heart disease. Pediatr Cardiol 27(4):408-413. https://doi.org/10.1007/s00246-006-0934-y

17. Andropoulos DB, Stayer SA, Diaz LK, Ramamoorthy C (2004) Neurological monitoring for congenital heart surgery. Anesth Analg 99(5):1365-1375. https://doi.org/10.1213/01.ANE.0000134808.52676.4D

18. Fang A, Allen KY, Marino BS, Brady KM (2019) Neurologic outcomes after heart surgery. Paediatr Anaesth 29(11):1086-1093. https://doi.org/10.1111/pan.13744

19. Andropoulos DB, Easley RB, Gottlieb EA, Brady K (2019) Neurologic injury in neonates undergoing cardiac surgery. Clin Perinatol 46(4):657-671. https:// doi.org/10.1016/j.clp.2019.08.003

20. Lynch JM, Buckley EM, Schwab PJ, McCarthy AL, Winters ME, Busch DR et al (2014) Time to surgery and preoperative cerebral hemodynamics predict postoperative white matter injury in neonates with hypoplastic left heart syndrome. J Thorac Cardiovasc Surg 148(5):2181-2188. https://doi.org/10.1 016/j.jtcvs.2014.05.081

21. Mulkey SB, Ou X, Ramakrishnaiah RH, Glasier CM, Swearingen CJ, Melguizo MS, Yap VL, Schmitz ML, Bhutta AT (2014) White matter injury in newborns with congenital heart disease: a diffusion tensor imaging study. Pediatr Neurol 51(3):377-383. https://doi.org/10.1016/j.pediatrneurol.2014.04.008

22. Te Pas AB, van Wezel-Meijler G, Bökenkamp-Gramann R, Walther FJ (2005) Preoperative cranial ultrasound findings in infants with major congenital heart disease. Acta Paediatr 94(11):1597-1603. https://doi.org/10.1111/j.1 651-2227.2005.tb01835.x

23. Bertholdt S, Latal B, Liamlahi R, Prêtre R, Scheer I, Goetti R et al (2014) Cerebral lesions on magnetic resonance imaging correlate with preoperative neurological status in neonates undergoing cardiopulmonary bypass surgery. Eur J Cardiothorac Surg 45(4):625-632. https://doi.org/10.1093/ejcts/ezt422

24. El-Gamal H, Parray AS, Mir FA, Shuaib A, Agouni A (2019) Circulating microparticles as biomarkers of stroke: a focus on the value of endothelialand platelet-derived microparticles. J Cell Physiol. 234(10):16739-16754. https://doi.org/10.1002/jcp.28499

\section{Publisher's Note}

Springer Nature remains neutral with regard to jurisdictional claims in published maps and institutional affiliations. 